\title{
Considerações anatômicas e análise de óleo essencial do hipanto e do fruto de Hennecartia omphalandra J. Poisson (Monimiaceae)
}

\author{
Carlos A. Marques, ${ }^{*, 1,2}$ Gilda G. Leitão, ${ }^{3}$ Humberto R. Bizzo, ${ }^{4}$ Walter M. Kranz, ${ }^{5}$ Ariane L. \\ Peixoto, ${ }^{6}$ Ricardo C. Vieira ${ }^{1}$
}

${ }^{1}$ Laboratório de Morfologia Vegetal, Departamento de Botânica, Universidade Federal do Rio de Janeiro, Av. Brigadeiro Trompowsky, s/n, Ilha do Fundão, 21941-590 Rio de Janeiro-RJ, Brasil,

${ }^{2}$ Centro Federal de Educação Tecnológica de Química de Nilópolis, R. Lúcio Tavares, 1045, Centro, 26530-060 Nilópolis-RJ, Brasil,

${ }^{3}$ Núcleo de Pesquisas de Produtos Naturais, Bloco H, Universidade Federal do Rio de Janeiro, Av. Brigadeiro Trompowsky, s/n, Ilha do Fundão, 21941-590, Rio de Janeiro-RJ, Brasil,

${ }^{4}$ Centro Nacional de Pesquisa de Tecnologia Agroindustrial de Alimentos, EMBRAPA, Av. das Américas, 29501, Guaratiba, 23020-470 Rio de Janeiro-RJ, Brasil,

${ }_{5}^{5}$ Instituto Agronômico do Paraná, Rodovia Celso Garcia Cid, Km 375, Três Marcos, 86047-902 Londrina-PR, Brasil,

${ }^{6}$ Instituto de Pesquisas Jardim Botânico do Rio de Janeiro, R. Jardim Botânico, 1008, Jardim Botânico, 22460-070 Rio de Janeiro-RJ, Brasil

\begin{abstract}
RESUMO: Descreve-se o estudo morfo-anatômico e a análise de óleo essencial do fruto de Hennecartia omphalandra J. Poisson (Monimiaceae), uma planta tóxica. A ocorrência de feixes recurrentes e de um anel descontínuo de braquiesclereides no hipanto; assim como a presença de células oleíferas no mesocarpo, de "idioesclereídes" formando o endocarpo e de células com espessamento parietal em rede, constituindo a testa da semente, foram considerados caracteres importantes que podem auxiliar na sua morfo-diagnose. A análise do óleo essencial dos frutos revelou a presença de monoterpenos, sesquiterpenos e álcoois sesquiterpênicos, sendo este o grupo mais significativo. Os componentes majoritários identificados foram o biciclogermacreno $(19,6 \%)$ e o $\beta$-felandreno $(8,7 \%)$, além do germacreno $\mathrm{D}(5,3 \%), \alpha$-bulneseno $(5,1 \%)$ e valerianol $(4,9 \%)$.
\end{abstract}

Unitermos: Hennecartia omphalandra, Monimiaceae, plantas tóxicas, fruto múltiplo, óleo essencial.

\begin{abstract}
Anatomical considerations and essential oil analysis of the hypanthium and the fruit of Hennecartia omphalandra J. Poisson (Monimiaceae)". The morphological and anatomical aspects of flower and fruit and the essential oil analysis of fruits of Hennecartia omphalandra J. Poisson (Monimiaceae), a toxic plant, are described in this paper. The presence of vascular recurrent bundles and of a ring of brachysclereids in the hypanthium; the oil cells in the mesocarp, the "idiosclereids" that constitutes the endocarp and cells with reticulated thick walls, shaping the seed coat were described as characters that may help in its diagnosis. The analysis of the essential oil of fruits showed the presence of monoterpenes, as well as sesquiterpenes hydrocarbons and alcohols, being the latter the most significant group. The major identified compounds were bicyclogermacrene (19.6\%); ß-felandrene $(8.7 \%)$; germacrene D $(5.3 \%) ; \alpha$ bulnesene $(5.1 \%)$ and valerianol $(4.9 \%)$.
\end{abstract}

Keywords: Hennecartia omphalandra, Monimiaceae, toxic plants, multiple fruit, fruit anatomy, essential oil.

\section{INTRODUÇÃO}

Desde épocas remotas as plantas tóxicas exercem um papel importante, seja através do uso como veneno de flechas ou como recurso em envenenamentos intencionais com fins políticos, militares ou pessoais (Schenkel et al., 2002). O estudo dessas plantas vem ganhando importância pois, além de esclarecer diferentes aspectos relativos aos casos de intoxicações e de identificar constituintes químicos capazes de exercer ação tóxica, pode ainda fornecer substâncias ativas para o desenvolvimento de fármacos e inseticidas (Vieira et al., 2002).

Neste contexto, a anatomia vegetal constituise em um instrumento eficaz, pois, além do aspecto descritivo, também pode contribuir através dos dados fornecidos pelo estudo de estruturas secretoras, possibilitando a elucidação de aspectos relativos ao 
armazenamento e secreção de metabólitos secundários. Contudo, os estudos sobre anatomia de plantas tóxicas ainda são escassos. Mencionam-se os trabalhos de Panizza et al. (1982), pela constatação de que os pêlos constituem os elementos mais importantes para o diagnóstico de Cannabis sativa L. (Cannabinaceae); de Milanez \& Monteiro-Neto (1956) sobre os laticíferos de Euphorbia pulcherrima Willd. (Euphorbiaceae) e de Guimarães et al. (1979) que caracterizaram anatomicamente a folha de Cestrum sendtnerianum Sendt. (Solanaceae) e verificaram a presença de alcalóides, através de testes histoquímicos. Já em Dieffenbachia picta Schott (Araceae), o estudo das células secretoras na folha foi determinante no esclarecimento do seu mecanismo de ação (Carneiro et al., 1989; Ferreira et al., 2006). Cabe ainda ressaltar que, no Brasil, a descrição da morfologia externa e interna de espécies vegetais que servem como base para o desenvolvimento de fármacos, é determinada pela RDC n 48 da ANVISA, de 16/03/2004 (Anvisa, 2005).

Em espécies de Monimiaceae os estudos anatômicos também são restritos e resumem-se, na sua grande maioria, à descrição dos órgãos vegetativos aéreos (Occhioni \& Lira, 1948; Metcalfe, 1987; Fischer et al., 1998; Palma et al., 2002).

Espécies pertencentes às famílias Monimiaceae, bem como de famílias próximas como Siparunaceae, são citadas pelo seu uso em medicina popular, como Siparuna apiosyce (Mart. ex Tul.)A.DC. (Siparunaceae), vulgarmente conhecida como limão-bravo, utilizada no tratamento de distúrbios gastrointestinais, febres, gripes e outros tipos de afecções (Brandão et al., 2006; Brandão et al., 2008). Mollinedia brasiliensis Schott ex Tul. (Monimiaceae), é considerada um forte antiespasmódico (Leitão et al., 1999) e Siparuna pauciflora (Beurl.) A. DC. (Siparunaceae), demonstrou atividade contra Plasmodium falciparum (Jenett-Siems et al., 2003). Estudos fitoquímicos em espécies de Monimiaceae têm destacado a presença de uma grande variedade de constituintes químicos, justificando a atividade biológica e o uso dessas espécies na medicina popular (Mendes et al., 2006; Ruiz et al., 2008). Peumus boldus Molina (Monimiaceae) é a espécie mais conhecida, sendo mencionada em diversas farmacopéias pelo seu uso contra dispepsias, náuseas e constipação intestinal, conforme mencionam Leitão et al. (1999) e Agra et al. (2007). Nessa espécie, encontram-se alcalóides benzilisoquinolínicos como boldina, isocordina e $\mathrm{N}$ metillaurotetanina (Pietta et al., 1988).

Hennecartia omphalandra J. Poisson. (Monimiaceae), popularmente conhecida como "canemeira", "pimenteira-do-mato" ou "arreganha" é considerada uma espécie tóxica, segundo o Centro de Investigações Toxicológicas/ SC, por ter causado grave intoxicação em crianças na cidade de Cândido de Abreu, PR, após a ingestão de sementes, segundo Schenkel et al. (2002). A ocorrência deste fato motivou o estudo

morfológico e anatômico do fruto de Hennecartia omphalandra J. Poisson, a fim de fornecer dados para a sua morfo-diagnose. Também foi realizado um estudo visando acompanhar o desenvolvimento do hipanto, desde o botão floral até o estágio de completa expansão das flores para melhor compreensão da estrutura dos frutos múltiplos. Foi feita a análise de óleo essencial dos frutos, como parte integrante do estudo fitoquímico e de atividade biológica desta espécie, na busca de constituintes químicos que possam corroborar, inclusive, com a atividade tóxica relatada.

\section{MATERIAL E MÉTODOS}

Material botânico - Flores femininas e frutos dos indivíduos estudados foram coletados na Chácara Recanto Beija-Flor, uma propriedade particular localizada no bairro Aviação Velha em Londrina, PR. A propriedade contém, dentro dos seus limites, um trecho remanescente de mata que Veloso et al. (1991) e SoaresSilva \& Barroso (1992) classificam como Floresta Estacional Semidecidual, onde se realizou a coleta de três indivíduos aleatoriamente escolhidos. Após a coleta e subseqüente identificação, o material botânico foi depositado e registrado no Herbário do Departamento de Botânica da Universidade Federal do Rio de Janeiro (RFA), sob o número 30.840.

Estudo morfo-anatômico - Para realização deste estudo foram processados botões florais, o hipanto nas flores femininas em antese, além de frutos recém fecundados, em estádios intermediários do desenvolvimento e frutos completamente desenvolvidos. As amostras foram fixadas em FPA preparado com etanol $70 \%$ e os fragmentos emblocados em Historesina Leica, sendo posteriormente seccionados ao micrótomo rotativo com espessura de 6-10 $\mu \mathrm{m}$. A coloração dos cortes foi feita utilizando-se Azul de toluidina 0,05\%, sendo montados entre lâmina e lamínula, usando-se bálsamo do Canadá sintético como meio de montagem. Os testes histoquímicos foram feitos em cortes de material fresco, utilizando-se floroglucina para identificação de lignina; lugol para identificar amido; sudan IV para substâncias de natureza lipofílica (Johansen, 1940) e, para a detecção de substâncias fenólicas, foi utilizada a mistura ácido acético glacial/ formaldeído/ $\mathrm{FeSO}_{4}$ (Ruzin, 1999) Para a dissociação do pericarpo, foi utilizado o reagente de Jeffrey (Johansen, 1940). As observações relativas à morfologia externa foram feitas ao microscópio estereoscópio Nikon SMZ 800 e as fotografias dos frutos foram obtidas através da captura de imagens em máquina fotográfica digital Canon. As fotomicrografias foram obtidas ao Fotomicroscópio III da Zeiss.

Extração e análise do óleo essencial - Realizouse a extração do óleo essencial, em 12/11/2003, de $151 \mathrm{~g}$ de frutos frescos (incluindo o hipanto) por hidrodestilação em um aparelho do tipo Clevenger por três horas, de onde se obteve $0,05 \mathrm{~mL}$ de óleo. $\mathrm{O}$ 
óleo essencial de Hennecartia omphalandra J. Poisson foi analisado no dia subseqüente por cromatografia gasosa (CG) em um equipamento Agilent HP 5890, série II, equipado com um detector de ionização de chama, mantido a $280{ }^{\circ} \mathrm{C}$ e uma coluna capilar Ultra $2(25 \mathrm{~m} \times 0,20 \mathrm{~mm} \times 0,33 \mu \mathrm{m})$, utilizando hidrogênio $\left(1,0 \mathrm{~mL} \cdot \mathrm{min}^{-1}\right)$ como gás carreador. A programação de temperatura do forno foi de 60 a $240{ }^{\circ} \mathrm{C}$, com incremento de $3{ }^{\circ} \mathrm{C}$ min $^{-1}$. A amostra, $1,0 \mu \mathrm{L}$ de uma solução a $1 \%$ do óleo essencial em hexano, foi injetada no modo com divisão de fluxo $(1: 100)$ em injetor mantido a $250{ }^{\circ} \mathrm{C}$. A quantificação foi realizada por normalização de área. A análise por espectrometria de massas foi realizada em sistema Agilent 5973N, acoplado a um cromatógrafo a gás Agilent 6890, equipado com uma coluna capilar HP5MS (30 m x 0,25 $\mathrm{mm} \times 0,25 \mu \mathrm{m})$, utilizando hélio como gás carreador a $1,0 \mathrm{~mL} \cdot \mathrm{min}^{-1}$. O detector de massas foi operado no modo impacto de elétrons com energia de $70 \mathrm{eV}$. Os demais parâmetros de operação foram os mesmos acima. Os espectros de massas foram comparados com aqueles da biblioteca do espectrômetro (Wiley 6th ed.) e com espectros disponíveis na literatura (Mac Lafferty \& Stanffer, 1989; Adams, 1995; 2001). Para a identificação também foi calculado o índice de Kovats, utilizando-se os dados de uma série homóloga de hidrocarbonetos alifáticos saturados $\left(\mathrm{C}_{7} \mathrm{a}_{26}\right)$ na mesma coluna e condições da análise de CG do óleo. Os índices de Kovats calculados foram comparados com índices da literatura (Adams, 1995; 2001) e a identificação dos componentes do óleo foi efetuada com dados de espectrometria de massas e do índice de Kovats.

\section{RESULTADOS E DISCUSSÃO}

H. omphalandra é um espécie dióica, onde os carpelos da flor feminina são circundados pelo hipanto. No material estudado, identificou-se um único óvulo por carpelo. Realizou-se a breve descrição dos óvulos, tendo como objetivo principal a observação dos tegumentos presentes, a fim de garantir a identificação mais segura das estruturas que envolvem as sementes em frutos desenvolvidos.

No óvulo, observado logo após fecundação da oosfera, observa-se a presença de dois tegumentos, calaza bem desenvolvida e um funículo longo, dando a este óvulo aspecto circinótropo, sendo a micrópila, de contorno irregular, formada pelo tegumento interno (Figuras 1A-B). O tegumento externo é constituído por quatro a cinco camadas de células e o tegumento interno por quatro a seis estratos celulares. Não foi observada presença de cutícula em microscopia óptica, tanto nas estruturas mais externas quanto nos tegumentos.

Endress \& Igershein (1997) relatam a presença de óvulo anátropo para os gêneros de Monimiaceae, porém, também mencionam a ocorrência de óvulo hemianátropo em Kibaropsis Vieillard ex Guillaumin.
Money et al. (1950) mencionam, em Monimiaceae, a presença de um único óvulo anátropo, com a micrópila direcionada para baixo ou para cima e Peixoto (1976) descreve em Hennecartia omphalandra J. Poisson um óvulo pêndulo, do tipo anátropo. Fahn (1985) define óvulo circinótropo como aquele em que o funículo é muito longo e rodeia o óvulo. É possível que, na espécie em estudo, a rafe sofra um alongamento após fecundação, fazendo com que a semente se torne circinótropa.

Morfologia externa do fruto - o hipanto que envolve o fruto caracteriza-se como uma estrutura receptacular acrescente, contínua, apresentando coloração parda a marrom e que abriga completamente os frutíolos, derivados de um gineceu apocárpico, fechando-se no ápice (Figuras 2B e 3). Na região apical desta estrutura formam-se lobos terminais intumescidos que se expandem tanto para fora quanto para o interior. Os frutos múltiplos, nos indivíduos coletados, são constituídos por um, dois ou três frutíolos (Figuras 2A, 2B e 3), caracterizados como drupas elipsóides. O comprimento médio dos diásporos (pericarpo+semente) foi de aproximadamente $1,6 \mathrm{~cm}$ e o diâmetro médio foi de aproximadamente $1,9 \mathrm{~cm}$ no fruto contendo apenas um frutíolo completamente desenvolvido (Figura 3). Já o fruto que contém dois frutíolos apresentou comprimento médio de aproximadamente $2,2 \mathrm{~cm}$ e diâmetro médio de aproximadamente 2,7 cm (Figura 2A). O fruto que abriga 3 drupas apresentou comprimento médio dos diásporos de aproximadamente $2,0 \mathrm{~cm}$ e diâmetro médio aproximado de 2,5 cm (Figura 2B). Em todos os tipos, o hipanto que envolve os frutos possui 5 pequenos lobos na região mais distal (Figura 2B).

Em muitos grupos de plantas, o ovário está estreitamente relacionado com tecidos extracarpelares, os quais podem desenvolver-se em conjunto, formando parte intimamente ligada à estrutura final. Tais uniões carpelares e extracarpelares conduzem a dificuldades terminológicas no que concerne à definição de fruto (Esau, 1977).

Barroso et al. (1999) definem fruto múltiplo como aquele originado do desenvolvimento do gineceu apocárpico de uma flor, sendo que cada carpelo constitui uma unidade carpológica e recebe a denominação de frutíolo. Portanto, a definição "fruto múltiplo" é adequada para o fruto estudado. Este é composto por drupas monospérmicas envolvidas pelo hipanto que se rompe de forma irregular (Figura 2A). Essa abertura, após maturação, pode fazer com que o fruto múltiplo seja confundido com um fruto capsular simples e, dessa forma, os frutíolos podem ser equivocadamente identificados como sementes (Figura 2A), conforme encontrado no registro do caso de intoxicação à que se refere Schenkel et al. (2002).

Descrição do hipanto - o hipanto é um exemplo de estrutura floral que possui origem extracarpelar (receptacular), sendo uma extensão do eixo floral (Harris \& Harris, 2001; Judd et al., 2002), mas que 
pode persistir no fruto, encobrindo-o de forma total ou parcial. Desta forma, o estudo dessa estrutura aderida ou fundida ao pericarpo dos frutos, requer a análise prévia da flor, a fim de esclarecer sua origem e aspectos relacionados ao seu desenvolvimento evitando, assim, equívocos relativos à sua identificação.

Os botões florais femininos, com um comprimento médio de $0,2 \mathrm{~cm}$ e diâmetro médio de 0,3 $\mathrm{cm}$ já apresentam uma estrutura receptacular acrescente $\mathrm{e}$ contínua, sem suturas, meatos ou concrescência a outras peças florais de natureza extracarpelar. Este receptáculo envolve completamente o gineceu apocárpico, apresentando-se espesso na base e, na medida em que se encaminha para o ápice, vai se tornando afilado. Nessa etapa do desenvolvimento, a extremidade do receptáculo ainda não se diferenciou nos lobos mais apicais do receptáculo (Figura 4).

Em secção longitudinal do botão floral feminino, o receptáculo acrescente, apresenta duas faces: uma dorsal e outra ventral, sendo a camada mais externa correspondente à epiderme uniestratificada, onde ocorrem tricomas tectores unicelulares. Subjacentes a protoderme observam-se 12-15 estratos de células parenquimáticas de aspecto uniforme. Já é possível observar células oleíferas em diferentes graus de diferenciação, além de dois anéis de feixes vasculares colaterais (Figura 5). O primeiro é proveniente do cilindro vascular do pedicelo. O outro anel de feixes é mais interno, localizado na região próxima à inserção dos carpelos (Figura 4).

Endress (1980) chama de tépalas esses lobos apicais que se expandem tanto para fora, quanto para dentro da flor, em direção ao gineceu. Caracteres anatômicos como a presença de células secretoras de óleo essencial, nos estratos subepidérmicos; de conteúdo extracelular mucilaginoso abundante secretado pelas células epidérmicas de aspecto papiloso, tornam essa estrutura muito semelhante a um estigma floral. Segundo Endress (1980) e Endress \& Igersheim (1997), é possível que tal estrutura atue como um estigma. Esta estrutura complexa é ilustrada pelas Figuras 6 e 7.

Em flores completamente expandidas, secções longitudinais da região mediana do hipanto (Figura 9) revelam a presença de epiderme uniestratificada, com tricomas tectores unicelulares e estômatos que raramente podem ser visualizados na face externa da epiderme. Já na face interna, as células epidérmicas possuem menores dimensões, ocorrendo tricomas tectores unicelulares, curtos ou longos que se desenvolvem em direção à cavidade existente entre este receptáculo e o gineceu apocárpico (Figura 10) já que, nesta espécie, o receptáculo envolve o gineceu, mas estes não estão concrescidos (Figuras 3 e 9).

Em posição subjacente à face externa da epiderme, ocorrem quatro a seis estratos de células parenquimáticas, seguidos por uma região onde se originam grupos de braquiesclereídes, formando um anel

descontínuo, em meio às demais células do parênquima fundamental (Figuras 10 e 11). Voltados para a face interna, subjacentes às esclereídes, ocorrem 14-16 estratos celulares parenquimáticos, onde se encontram feixes vasculares colaterais. Em seção longitudinal, o sistema vascular mantém a conformação de dois anéis, tal como descrito no botão floral (Figura 4). Nesta etapa do desenvolvimento, um padrão de distribuição dos feixes é estabelecido. $\mathrm{O}$ anel de feixes mais externo, proveniente do cilindro vascular do receptáculo, apresenta feixes vasculares com xilema voltado para o interior e o floema voltado para o exterior. Já o anel de feixes mais interno, apresenta disposição inversa. $\mathrm{O}$ xilema fica voltado para o exterior e o floema volta-se para o interior. Da porção mediana para a porção distal do receptáculo acrescente, notam-se regiões onde os dois tipos feixes vasculares se unem (Figura 8).

Smith \& Smith (1942), ao estudarem a flor de Darbya A. Gray (Santalaceae), verificaram que o ovário ínfero é fusionado ao receptáculo em forma de cúpula. Os autores mencionam dois tipos de feixes: os feixes mais externos, onde o xilema está voltado para o interior e o floema está voltado para o exterior e os feixes mais internos, dispostos de forma invertida e denominados "feixes recurrentes" por esses autores. Esau (1977) menciona que, em algumas flores epígenas, certos feixes apresentam orientação invertida de xilema e floema. Esse tipo de arranjo é interpretado como indicação de que o ovário se encontra encravado em tecidos provenientes do receptáculo, nos quais a inversão dos feixes resulta de uma invaginação do receptáculo. A ausência de feixes invertidos, por outro lado, é interpretada como evidência de que os tecidos extracarpelares são de natureza apendicular (tubo floral). Fahn (1985) menciona que no hipanto de Rosa helenae Rehder \& E.H. Wilson (Rosaceae) os tecidos do receptáculo também se fundem com os do gineceu, de forma que há uma invaginação do receptáculo e um "pregueamento" dos tecidos do ovário, em direção ao receptáculo. Por isso, observam-se três anéis de feixes vasculares com a seguinte disposição: no anel mais interno, o xilema está voltado para fora e o floema para dentro, nos dois anéis mais externos, o xilema está voltado para dentro e o floema está voltado para fora.

Nos frutos, o hipanto se expande, acompanhando o crescimento que ocorre nas estruturas mais internas, representadas pelos frutíolos que se diferenciam e se desenvolvem sobre a base do receptáculo. A epiderme no hipanto, que agora envolve os frutos, mantém-se uniestratificada, porém torna-se glabra em ambas as faces. A face interna da epiderme, adjacente ao epicarpo, mantém um arranjo compacto e mostra uniformidade no tamanho, na forma das células e na presença de amido, confirmada pelo teste com lugol (Figura 12). Nos estratos subjacentes à face externa da epiderme, verifica-se a presença de cinco ou seis camadas de células do parênquima fundamental, seguidos pela 
região formada por braquiesclereídes em grupos (Figura 12), tal como observados na flor feminina (Figuras $10 \mathrm{e}$ 11) e que mantêm a conformação de anel descontínuo. Com a diferenciação e o desenvolvimento do fruto, há um aumento da área ocupada pelas braquiesclereídes, resultando na compactação dos estratos de células parenquimáticas localizadas entre a face interna da epiderme e essas esclereídes (Figura 12). Entre essas células de parênquima encontram-se idioblastos que armazenam conteúdo lipofílico ou amido, além de feixes vasculares colaterais.

A disposição dos feixes vasculares permanece peculiar. Pode-se verificar a presença de feixes onde o xilema está voltado para a face externa e o floema para a face interna, feixes com a posição invertida (feixes recurrentes), tal comoé observadonaflore aindaépossível visualizar outros feixes em posição intermediária, onde o xilema fica voltado para a região apical do receptáculo e o floema volta-se em direção à base do receptáculo, de forma que nem xilema e nem floema ficam voltados para as faces externa ou interna. Há também regiões onde esses feixes se unem (Figura 13). Valente et al. (1994), ao analisarem o fruto de Laguncularia racemosa (L.) C.F.Gaertn. (Combretaceae), também caracterizaram o ovário fundido ao receptáculo pela presença de feixes recurrentes.

Anatomia do pericarpo e semente - O pericarpo possui arranjo compacto, sendo fortemente aderido à semente. Secções longitudinais do fruto revelaram um epicarpo glabro constituído por uma camada de células. Tais células apresentam conteúdo escuro que muitas vezes impede sua visualização (Figura 14). Contudo, no teste histoquímico para substâncias fenólicas obtevese resultado negativo. A parede periclinal externa e as paredes anticlinais apresentam impregnação por cutina. Em cortes mais finos, o epicarpo apresenta células com numerosos grãos de amido e, por vezes, pequenos cristais de oxalato de cálcio. Os vacúolos são evidentes em algumas células. Em algumas regiões, ocorre um segundo estrato descontínuo. Esta descrição complementa as descrições provenientes dos estudos da morfologia externa que mencionam a ocorrência de um epicarpo fino (Peixoto, 1976). A mesma característica também pode ser observada em outros gêneros da ordem como Siparuna Aubl. (Siparunaceae) (Barroso et al., 2002); contudo, não se pode considerá-la um padrão para a família Monimiaceae. Em espécies de Mollinedia Ruiz et Pavon (Monimiaceae), o epicarpo é rugoso (Peixoto et al., 2001). Em frutos de Decarydendron Danguy (Monimiaceae), o epicarpo é carnoso, sendo a "casca" superficial parenquimática, repleta de braquiesclereídes (Lorence, 1987).

O mesocarpo ocupa a maior área do pericarpo (Figuras 14 e 15), sendo formado por células parenquimáticas maiores do que as do epicarpo, apresentando paredes delgadas, núcleo evidente, onde se pode observar o nucléolo e um grande vacúolo.
Destaca-se ainda a presença de células secretoras de óleo essencial, evidenciado pelo teste histoquímico (Figuras 14 e 15), com paredes impregnadas por suberina que também reagem positivamente ao sudan IV. Nessa região, ocorrem idioblastos formados por pequenos cristais. Na região próxima ao endocarpo, verifica-se a presença de feixes vasculares colaterais. A presença de células secretoras de óleo essencial é referida para muitos gêneros da família Monimiaceae (Money et al., 1950). Baas \& Gregory (1985) e Metcalfe (1987) mencionam a ocorrência de células secretoras de óleo essencial em órgãos vegetativos de diversos gêneros dessa família e Endress \& Igershein (1997) relatam a presença destas células na flor. Contudo, a ocorrência destas estruturas secretoras nos frutos ainda não havia sido descrita para o gênero Hennecartia J. Poisson.

Em um dos indivíduos estudados observou-se que o estrato mais interno do mesocarpo é formado por células de grandes dimensões (Figura 15) sendo que, em algumas destas, é possível visualizar gotículas de óleo no vacúolo. Nos frutos mais amadurecidos, esta camada sofre colapso e, desta forma, não pode ser perfeitamente visualizada. É possível que tal fato faça parte de uma seqüência de eventos que visam liberar a unidade de dispersão. Sabe-se que, em drupas, a unidade de dispersão pode ser constituída pelo endocarpo preso à semente, tal como ocorre em espécies da família Lauraceae (Morais \& Paoli, 1996).

$\mathrm{O}$ endocarpo (Figuras 16 e 17) caracteriza-se por uma região espessa e compacta de esclereídes que se ramificam em várias direções, unindo-se fortemente entre si (Figura 17). A Figura 18 mostra esclereídes isoladas, após dissociação do endocarpo. Rao \& Bhupal (1973) propõem o termo "polirramificado", para as astroesclereídes que apresentam variações na sua forma. Os autores afirmam ainda que toda esclereíde idioblástica ramificada varia em algum grau e que o prefixo "idio" (= estranho, peculiar), representa um aspecto comum para todos os tipos ramificados. Pelo fato de não ser um termo específico para determinar a variação de um só tipo de esclereíde, como no tipo poliramificado, e que por isso não perde o sentido ou a validade, no caso de se encontrarem pequenas variações na sua forma, optou-se por denominar as esclereídes que constituem o endocarpo de "idioesclereídes" (Figuras 17 e 18).

A presença de endocarpo lignificado é uma característica encontrada nos gêneros que constituem a família Monimiaceae (Lorence, 1985). As drupas em geral, apresentam endocarpo duro e resistente, devido à presença de esclereides cujo tipo é pouco variável na ordem Laurales. Em Nectandra megapotamica (Spreng.) Mez (Lauraceae), o endocarpo é constituído por macroesclereídes (Souza et al., 2003). Em Endlicheria paniculata (Spreng.) J.F. Macbr. (Lauraceae), menciona-se a ocorrência de células em paliçada, com paredes espessas (Morais \& Paoli, 1996) e no gênero Decarydendron Danguy (Monimiaceae), o endocarpo 
é composto por esclereídes colunares fusiformes, orientados radialmente e densamente encaixados (Lorence, 1987). Desta forma, as idioesclereídes que compõem o endocarpo dos frutíolos de $H$. omphalandra são diferentes das demais, descritos até então para a família.

Segundo Esau (1977), drupa é um fruto carnoso derivado de ovário súpero caracterizado por endocarpo pétreo, mesocarpo carnoso e exocarpo fino, constituído por epiderme e colênquima subepidérmico. Basendo-se nessa definição de drupa pode-se denominar a camada constituída por esclereídes, em H. omphalandra, como sendo o endocarpo. Soma-se a isso o fato de que a unidade de dispersão, nas drupas, é constituída pelo endocarpo preso à semente; ou seja, o endocarpo é a camada que se encontra fortemente aderida à testa da semente.

A testa da semente, constituída por seis a doze estratos, é formada por células parenquimáticas, com espessamentos celulósicos predominantemente reticulados (Figuras 16 e 19). Embora também possam ocorrer espessamentos em faixas, estes são muito pouco freqüentes.

O tégmem forma uma estreita faixa constituída por três ou quatro estratos celulares (Figuras 16 e 19). $\mathrm{O}$ endosperma em contato com o tégmem (Figura 16) abrange a maior parte da semente, contendo células parenquimáticas de dimensões variáveis que possuem pequenos vacúolos e grãos de amido. Lorence (1985) menciona, em Monimia Thouars (Monimiaceae), a presença de tégmem com uma única camada de células alongadas retangulares, revestindo o endosperma abundante. $\mathrm{O}$ tégmen em $H$. omphalandra possui quatro estratos celulares.

O embrião é diminuto e encontra-se voltado para a região mais apical do endosperma. Nos embriões que se encontram na fase de torpedo (Figura 20), em frutíolos ainda não completamente maduros, obtevese melhor visualização das diferentes regiões que os constituem, em secção longitudinal, sendo que as regiões correspondentes a protoderme, meristema fundamental e procâmbio já podem ser perfeitamente visualizadas nos cotilédones, nesta etapa do desenvolvimento. A presença de um embrião diminuto, imerso em um endosperma abundante, reto, axial e com cotilédones ovais, constitui caracteres típicos desta família (Barroso et al., 1999).

Análise do óleo essencial - A composição química do óleo essencial é mostrada na Tabela 1 . O óleo essencial de $H$. omphalandra é constituído por cerca de 47 constituintes químicos entre hidrocarbonetos monoterpênicos e sesquiterpênicos, além de álcoois sesquiterpênicos e de um aldeído (dodecanal). A identificação das substâncias presentes no óleo essencial foi feita através da comparação dos seus índices de Kovats calculados com os da literatura (Adams, 1995; 2001) e também através da comparação de seus espectros de massas com os da literatura (MacLafferty

\& Stanffer, 1989). Dessa forma, foi possível identificar 40 constituintes químicos, correspondendo a $85,1 \%$ do total. A presença de 33 sesquiterpenos caracteriza este grupo como o mais significativo dentre as substâncias encontradas. Destes, 14 são álcoois sesquiterpênicos. Com isso, a soma de sesquiterpenos e álcoois sesquiterpênicos correspondem a $70,2 \%$ do total da mistura que constitui o óleo essencial. Observou-se ainda a ocorrência de 13 monoterpenos, o que corresponde a $27,7 \%$ e um hidrocarboneto (aldeído), correspondente a $2,1 \%$ do total. O constituinte químico majoritário é um sesquiterpeno, o biciclogermacreno $(19,6 \%)$, seguido do $\beta$-felandreno $(8,7 \%)$. Outros sesquiterpenos, como germacreno $\mathrm{D}(5,3 \%), \alpha$-bulneseno $(5,1 \%)$ e valerianol $(4,9 \%)$, também estão presentes em proporções significativas (Figuras 21 e 22).

Pela comparação dos espectros de massas, bem como pelo índice de Kovats calculado, sugere-se que a terceira substância citada na Tabela 1 corresponda a um monoterpeno bicíclico, provavelmente de estrutura do tipo pinano (Figura 22f) como o $\beta$-pineno, presente no óleo essencial. Entretanto, somente através da comparação visual com os dados bibliográficos disponíveis, não foi possível determinar qual é o monoterpeno bicíclico ocorrente no respectivo tempo de retenção observado na Tabela 1.

Ainda na região dos monoterpenos, pode-se verificar a presença de $\beta$-felandreno (Figuras 21 e 22a), sendo este o segundo constituinte mais abundante no óleo essencial analisado $(8,7 \%)$. Além desse, ainda se observa ocorrência de $\alpha$-felandreno $(0,4 \%)$ (Tabela 1). Sabe-se que teores de felandreno superiores a $5 \%$ são indesejáveis pela sua ação cardíaca (Simões \& Spitzer, 2002). O óleo essencial extraído dos frutos de $H$. omphalandra contém teores de felandreno que ultrapassam esse valor $(9,1 \%)$. Entretanto, os óbitos ocorridos pela ingestão de frutos e sementes da espécie estudada foram precedidos por sintomas semelhantes aos de intoxicação por cianeto, fato que ainda está sendo investigado. Desta forma, não se pode considerar que o felandreno seja a principal substância causadora da intoxicação. No entanto, a presença de altos teores deste constituinte químico no óleo essencial permite considerar que a ocorrência dessa substância em altos teores possa ser mais um fator que contribui para a toxidez do fruto.

A presença de sesquiterpenos, como constituintes majoritários do óleo essencial, pode ser observada em espécies dos gêneros Mollinedia Ruiz et Pavon (Monimiaceae) e Siparuna Aubl. (Siparunaceae). Em Hennecartia pode-se observar o mesmo padrão. Em Siparuna macrotepala Perk. (Siparunaceae), sesquiterpenos do tipo cadinano, como cadaleno e calameneno são referidos como componentes principais do óleo extraído de folhas e ramos (El-Seedi et al., 1994). Já em Siparuna guianensis Aubl. (Siparunaceae), um derivado oxidado do $\beta$-elemeno-curzenona foi 
Tabela 1. Constituintes químicos presentes no óleo essencial dos frutos múltiplos de H. omphalandra J. Poisson. IK - índice de Kovats; N.I. - não identificado; $\mathrm{t}$ - traço.

\begin{tabular}{|c|c|c|c|c|c|}
\hline Nome constituinte & $\begin{array}{c}\text { Tempo retenção } \\
\text { (min.) }\end{array}$ & Área (\%) & $\begin{array}{c}\text { IK } \\
\text { calculado }\end{array}$ & IK literatura & Referência utilizada \\
\hline N.I & 4,872 & 0,72 & 917 & - & - \\
\hline tricicleno & 5,052 & 2,10 & 926 & 926 & $\mathrm{a}$ \\
\hline monoterpeno bicíclico & 5,411 & 3,34 & 942 & - & $\mathrm{b}, \mathrm{c}$ \\
\hline sabineno & 6,048 & 1,07 & 969 & 975 & $\mathrm{~b}$ \\
\hline$\beta$-pineno & 6,146 & 0,36 & 973 & 980 & $\mathrm{a}$ \\
\hline$\beta$-mirceno & 6,518 & 0,40 & 987 & 991 & $\mathrm{a}$ \\
\hline$\alpha$-felandreno & 6,933 & 0,44 & 1002 & 1005 & $\mathrm{a}$ \\
\hline$\delta$-3-careno & 7,117 & 0,84 & 1009 & 1011 & a \\
\hline$\alpha$-terpineno & 7,314 & 0,21 & 1015 & 1018 & $\mathrm{a}$ \\
\hline p-cimeno & 7,579 & 0,21 & 1024 & 1026 & $\mathrm{a}$ \\
\hline$\beta$-felandreno & 7,716 & 8,74 & 1028 & 1031 & a \\
\hline$\gamma$-terpineno & 8,746 & 0,55 & 1058 & 1062 & $\mathrm{a}$ \\
\hline terpinoleno & 9,823 & 0,49 & 1086 & 1088 & $\mathrm{a}$ \\
\hline$\alpha$-cubebeno & 20,850 & 0,29 & 1347 & 1351 & $\mathrm{a}$ \\
\hline$\beta$-elemeno & 22,701 & 3,04 & 1388 & 1391 & a \\
\hline dodecanal & 23,215 & 1,80 & 1399 & 1407 & $\mathrm{a}$ \\
\hline$\alpha$-gurjuneno & 23,420 & 0,91 & 1404 & 1409 & $\mathrm{a}$ \\
\hline$E$-cariofileno & 23,834 & 3,94 & 1415 & 1418 & $\mathrm{a}$ \\
\hline trans- $\alpha$-bergamoteno & 24,553 & 0,64 & 1432 & 1436 & $\mathrm{a}$ \\
\hline aromadendreno & 24,655 & 1,36 & 1435 & 1439 & $\mathrm{a}$ \\
\hline$\alpha$-guaieno & 24,861 & 0,98 & 1440 & 1440 & $\mathrm{~b}$ \\
\hline$\alpha$-humuleno & 25,275 & 0,98 & 1450 & 1454 & $\mathrm{a}$ \\
\hline seychelleno & 25,583 & 0,74 & 1457 & 1460 & $\mathrm{a}$ \\
\hline$\gamma$-muuroleno & 26,263 & 1,13 & 1473 & 1477 & $\mathrm{a}$ \\
\hline germacreno D & 26,447 & 5,30 & 1477 & 1480 & $\mathrm{a}$ \\
\hline$\beta$-selineno & 26,673 & 2,16 & 1482 & 1485 & $\mathrm{a}, \mathrm{c}$ \\
\hline biciclogermacreno & 27,105 & 19,58 & 1490 & 1494 & $\mathrm{a}$ \\
\hline trans- $\beta$-guaieno & 27,272 & 0,78 & 1494 & 1503 & $\mathrm{~b}$ \\
\hline$\alpha$-bulneseno & 27,477 & 5,15 & 1500 & 1505 & $\mathrm{~b}$ \\
\hline N.I. & 27,849 & 0,74 & 1509 & - & - \\
\hline$\gamma$-cadineno & 27,930 & $\mathrm{t}$ & 1512 & 1513 & $\mathrm{a}$ \\
\hline$\delta$-cadineno & 28,238 & 1,74 & 1520 & 1524 & $\mathrm{a}$ \\
\hline germacreno B & 29,701 & 0,36 & 1556 & 1561 & $\mathrm{~b}$ \\
\hline ledol & 29,987 & 0,85 & 1563 & 1565 & $\mathrm{a}$ \\
\hline espatulenol & 30,440 & 3,72 & 1574 & 1576 & $\mathrm{~b}, \mathrm{c}$ \\
\hline N.I. & 30,688 & 5,42 & 1580 & - & - \\
\hline guaiol & 30,975 & 1,72 & 1587 & 1595 & $\mathrm{a}$ \\
\hline N.I. & 31,082 & 1,07 & 1589 & - & - \\
\hline N.I. & 31,411 & 1,14 & 1596 & - & - \\
\hline N.I. & 31,860 & 0,35 & 1609 & - & - \\
\hline N.I. & 32,232 & 1,58 & 1619 & - & - \\
\hline epi-cubenol & 32,437 & 0,34 & 1624 & 1627 & $\mathrm{a}$ \\
\hline cis-cadina-4-eno-7-ol & 32,852 & 1,99 & 1635 & 1637 & $\mathrm{~b}$ \\
\hline cubenol & 32,971 & 2,06 & 1638 & 1642 & $\mathrm{a}$ \\
\hline$\alpha$-muurulol & 33,159 & 0,45 & 1643 & 1645 & $\mathrm{a}$ \\
\hline valerianol & 33,467 & 4,92 & 1651 & 1655 & $\mathrm{a}$ \\
\hline$\alpha$-bisabolol & 34,703 & 2,54 & 1683 & 1683 & $\mathrm{a}$ \\
\hline
\end{tabular}

a - Adams (1995); b - Adams (2001); c - Mac Lafferty \& Stanffer (1989).

identificado como constituinte majoritário, além de outros como miristicina e metil-eugenol, presentes em quantidades significativas no óleo essencial (Antonio et al., 1984). Já em Peumus boldus Molina (Monimiaceae), encontram-se álcoois como cineol, linalool, $\alpha$-fenchol e terpinen-4-ol, além de fenilpropanóides (eugenol) como componentes do óleo essencial (Jorge-Neto et al., 1989;
Bruneton, 1991). Em H. omphalandra, encontraram-se 14 álcoois terpênicos, sendo que o valerianol $(4,9 \%)$ está entre os constituintes majoritários (Figura 22e). Em espécies de famílias próximas, como Aristolochiaceae, os sesquiterpenos também se encontram presentes em maior proporção no óleo essencial, sendo o biciclogermacreno o principal constituinte do óleo de 

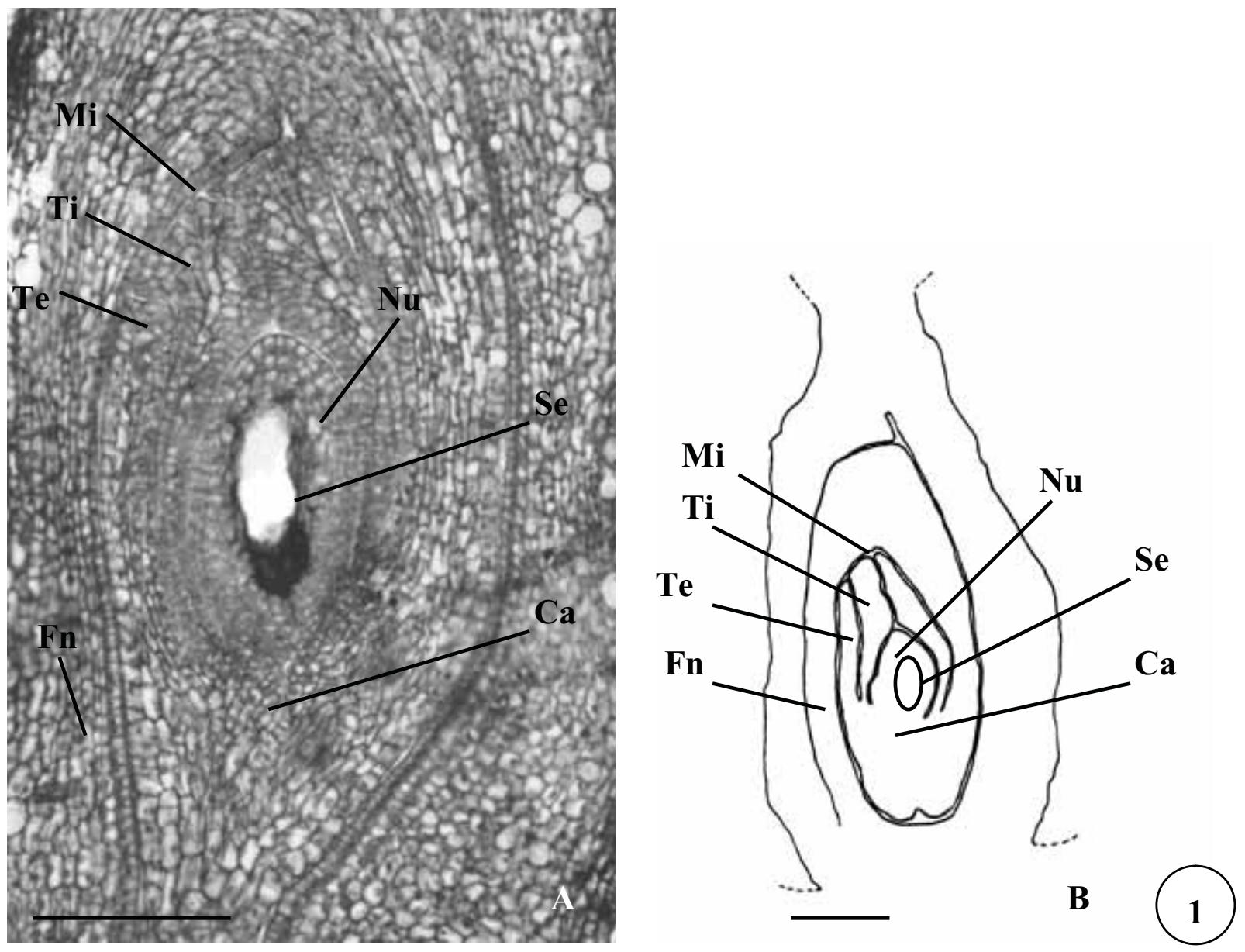

Figura 1. Estruturas que compõem o óvulo, com oosfera recém fecundada, em Hennecartia omphalandra (A) e seu respectivo esquema representativo (B). Ti - tegumento interno; Te - tegumento externo; Mi - micrópila; Fn - funículo; Ca - calaza; $\mathrm{Nu}$ nucelo; Se - saco embrionário. Barra $100 \mu \mathrm{m}$.

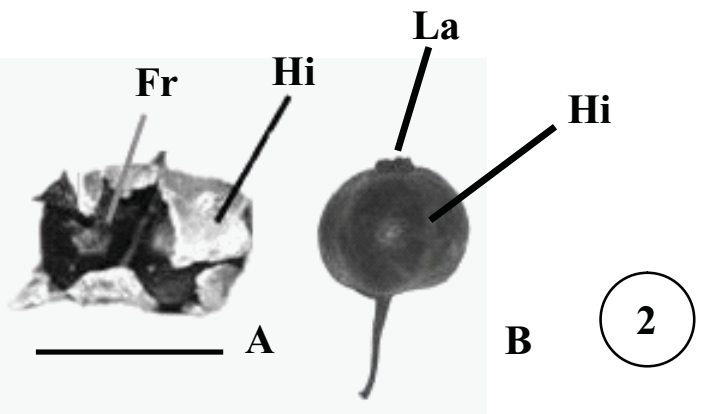

Figura 2. Variabilidade morfológica nos frutos de Hennecartia omphalandra. A - fruto múltiplo contendo dois frutíolos. B fruto múltiplo com três frutíolos. Barra $=2,7 \mathrm{~cm}$. Hi - hipanto; La - lobos apicais; Fr - frutíolos.

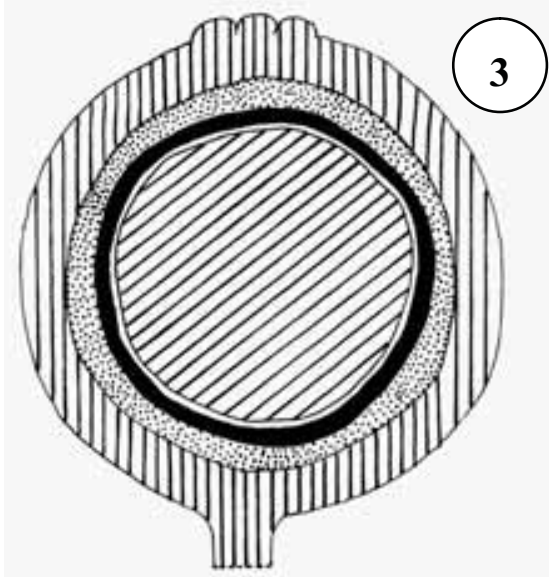

Figura 3. $H$. omphalandra: Esquema do fruto, contendo 1 frutíolo, em secção longitudinal. Barra $=1,6 \mathrm{~cm}$.

|l|l| Hipanto; $\square$ Epicarpo; 器: Mesocarpo;

Endocarpo; $\square$ Testa; $\square$ Tégma;

VIIA Endosperma 


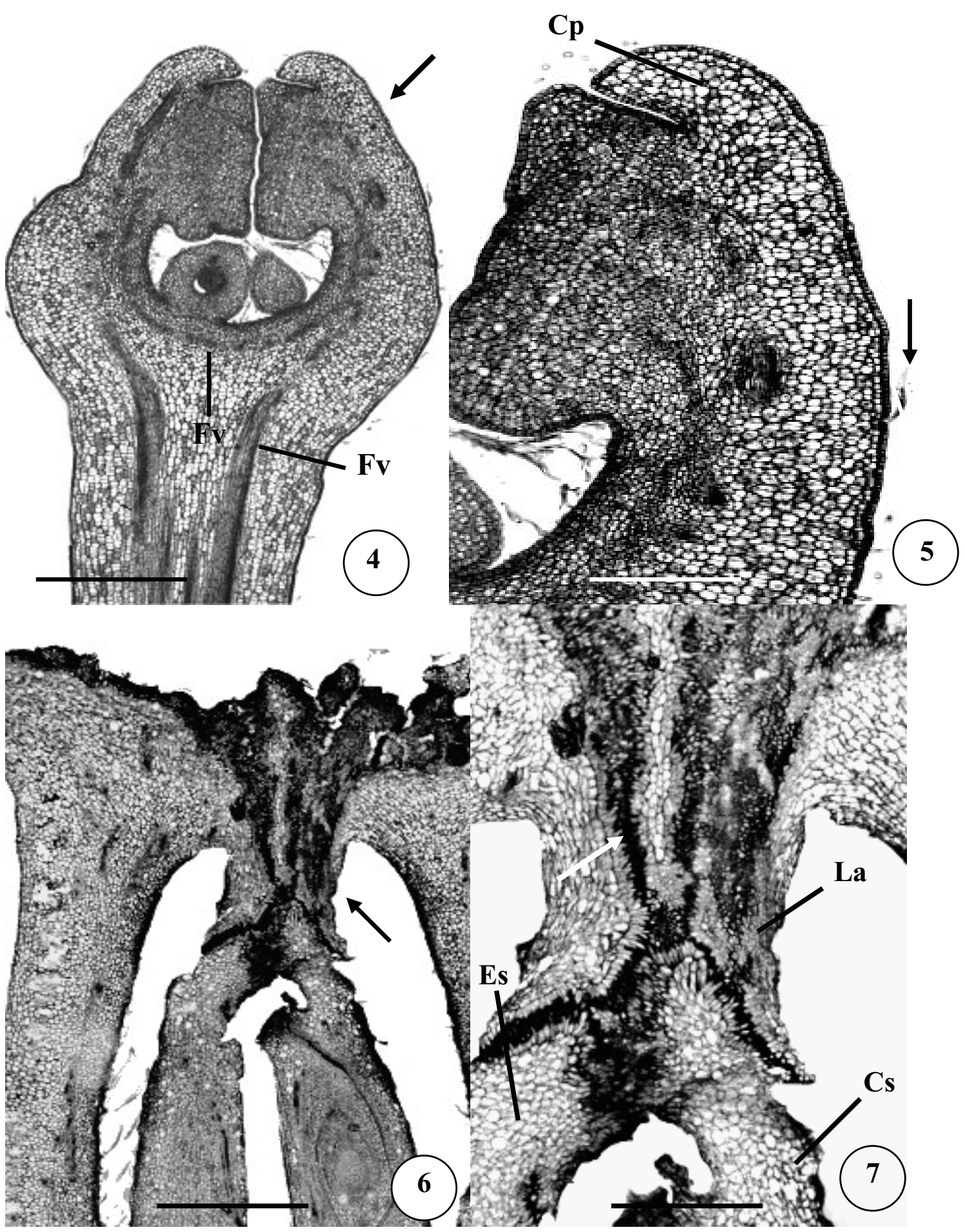

Figuras 4-7. Botão floral e flor feminina completamente expandida em $H$. omphalandra. Fig. 4. Botão floral em seção longitudinal, mostrando o hipanto em estágio inicial de diferenciação (seta) e os 2 anéis de feixes vasculares. Barra $250 \mu \mathrm{m}$. Fig. 5. Detalhe do hipanto no botão floral, onde se observam a face externa da epiderme com tricomas (seta), os estratos de células parenquimáticas e feixes vasculares. Barra $100 \mu \mathrm{m}$. Fig. 6. Flor completamente expandida, mostrando os lobos apicais do receptáculo que se invaginam (seta), unindo-se aos estigmas. Barra $250 \mu \mathrm{m}$. Fig. 7. Detalhe da região onde os lobos apicais que se invaginam se unem aos estigmas, sendo o meio extracelular preenchido por conteúdo (seta). Barra $100 \mu \mathrm{m}$. Cp - células parenquimáticas; Fv - feixes vasculares; La - lobos apicais internos; Es - estigma; Cs - células secretoras. 


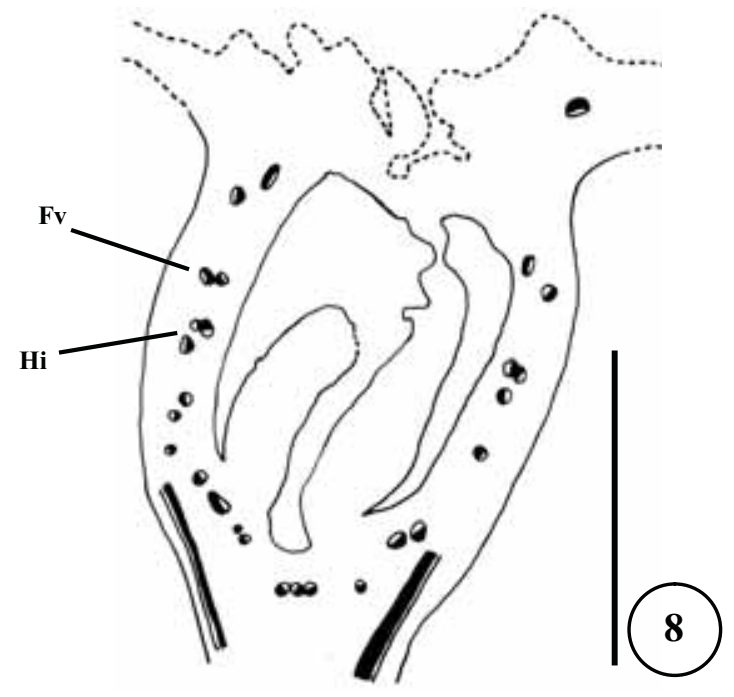

Figura 8. Distribuição e disposição dos feixes vasculares na flor feminina de $H$. omphalandra, em seção longitudinal. Barra 2,5 mm. Fv (Feixe vascular), Hi (Hipano).

Xilema, $\square$ Floema

Aristolochia argentina Gris. (Priestap et al., 2003). Já Leitão et al. (1991), ao analisarem óleos de espécies brasileiras de Aristolochiaceae identificaram como constituintes majoritários dos óleos essenciais estudados o $\alpha$-humuleno em Aristolochia birostis Ducke, Aristolochia macroura Gomes e Aristolochia papillaris Mast, $n$-undecano em Aristolochia cymbifera M.E.Zucc, $\beta$-cariofileno e germacreno D em Aristolochia gigantea M.E. Zucc, $\alpha$-copaeno em Aristolochia rodriguesia Hoeh e (E)-nerolidol e decano em Aristolochia triangularis C. St.. Em Siparunaceae, também se verificou a presença de biciclogermacreno no óleo essencial de quimiotipos amazônicos de Siparuna guianensis Aubl. (Siparunaceae) (Andrade et al., 2004). Segundo Gottlieb (1972), sesquiterpenos interrelacionados do eudesmano e do germacrano foram localizados nos gêneros Lindera Thunb. e Neolitsea (Benth.) Merr. (Lauraceae) e em outras famílias da subclasse Magnoliidae. Desta forma, observa-se que o gênero Hennecartia não foge ao padrão descrito por Gottlieb (1972), pois, além do biciclogermacreno, presente como componente principal (Figuras 21 e 22c), ainda se pode encontrar outros sesquiterpenos, como o germacreno $\mathrm{B}$ e, principalmente, o germacreno $\mathrm{D}$, que também está presente em quantidade significativa (Tabela 1). Germacreno D (Figura 22b) e germacreno B possuem estrutura extremamente semelhante, diferindo entre si apenas pela posição da dupla ligação. Todavia, essa pequena diferença origina espectros de massa distintos que permitem identifica-los com segurança. Cabe ressaltar que o germacreno D é o terceiro constituinte mais abundante do óleo essencial analisado, enquanto o germacreno B ocorre em proporção pouco significativa $(0,3 \%)$. Já o biciclogermacreno (Figura 22c), possui espectro de massas bem característico que o difere dos germacrenos anteriormente mencionados, já que seu esqueleto é ligeiramente diferente do ciclodecadieno que caracteriza os germacrenos, por ser um sesquiterpeno bicíclico, neste caso, o 3,7,11,11-tetrametilbicicloundeca-2,6-dieno (Figura 22c). A presença deste sesquiterpeno também pode ser verificada em outras espécies de Monimiaceae e Siparunaceae como Mollinedia schottiana (Spreng.) Perkins, Mollinedia glaziovii Perkins e Siparuna guianensis Aubl. (Moreira et al., 2001; Andrade et al., 2004).

Famílias que possuem espécies ricas em óleos essenciais como Lauraceae e Myristicaceae são relativamente pobres em espécies produtoras de alcalóides e ineficientes na variação do tema benziltetraidroisoquinolínico. Em oposição, famílias que produzem uma variedade de alcalóides deste tipo, como Annonaceae e Monimiaceae são relativamente pobres em óleos essenciais. Em resumo, o bloco magnoleano (sensu Dahlgren, 1980) e talvez com ele, as angiospermas em geral, se originam a partir de espécies dotadas de células oleíferas ricas em fenilpropanóides e terpenóides (Gottlieb \& Salatino, 1987). De fato, em famílias basais de angiospermas como Lauraceae e Monimiaceae (APG, 2003; Barbosa-Filho et al., 2008), verifica-se a presença de células secretoras de óleo essencial e/ou mucilagem, tendência tão característica que possui, inclusive, valor sistemático. Desta forma, a identificação de constituintes dos óleos essenciais, bem como de suas células secretoras, nos diferentes órgãos, ganha também importância sistemática.

Com base nos resultados obtidos, podemse destacar como caracteres farmacognósticos mais relevantes:

- A ocorrência de feixes vasculares recurrentes, além da presença de um anel descontínuo de braquiesclereídes no hipanto.

- A ocorrência de células secretoras de óleo essencial no mesocarpo, a presença de "idioesclereídes" que constituem o endocarpo e a ocorrência de células com espessamento parietal em rede, formando a testa da semente.

- A identificação do biciclogermacreno (19,6\%) como constiuinte químco majoritário do óleo essencial, seguido por $\beta$-felandreno $(8,7 \%)$, germacreno $\mathrm{D}(5,3 \%)$, $\alpha$-bulneseno $(5,1 \%)$ e valerianol $(4,9 \%)$ destacando-se, ainda, a ocorrência de teores de felandreno superiores a $5 \%$, mencionado na literatura como indesejável pela sua ação tóxica.

\section{AGRADECIMENTOS}

À Coordenação de Aperfeiçoamento de Pessoal de Nível Superior (CAPES) e ao Conselho Nacional de Desenvolvimento Científico e Tecnológico (CNPq) pelas bolsas concedidas e à Fundação Universitária José Bonifácio (FUJB) pelo suporte financeiro. 


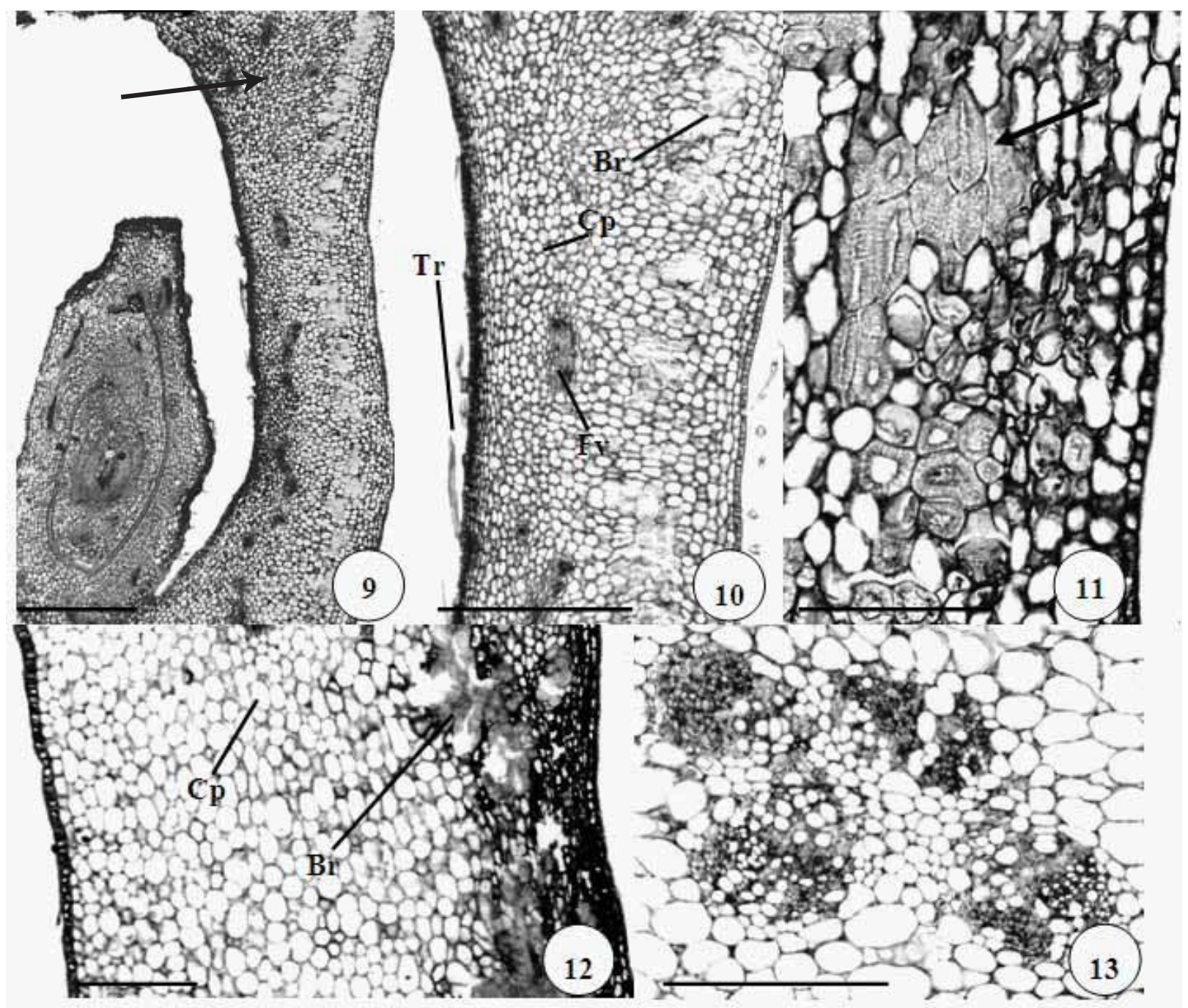

Figuras 9-13. Secções longitudinais da flor feminina completamente expandida e do hipanto no fruto de H. omphalandra. Fig. 9. Hipanto (seta) envolvendo o gineceu apocárpico. Barra $250 \mu \mathrm{m}$. Fig. 10. Detalhe da estrutura anterior, onde são observados tricomas, os estratos de células parenquimáticas subjacentes às 2 faces da epiderme, feixes vasculares e braquiesclereides em grupos. Barra $200 \mu \mathrm{m}$. Fig. 11. Detalhe dos braquiesclereides (seta). Barra $100 \mu \mathrm{m}$. Fig. 12. Hipanto em detalhe no fruto, destacando a ocorrência de braquiesclereides e feixes vasculares em meio às células parenquimáticas. Barra $250 \mu \mathrm{m}$. Fig. 13. Feixes vasculares colaterais dispostos em diferentes posições, em relação às faces externa e interna do receptáculo. Barra $100 \mu \mathrm{m}$. Tr-tricomas; Cp-células parenquimáticas; Fv-feixes vasculares; Br-braquiesclereides. 


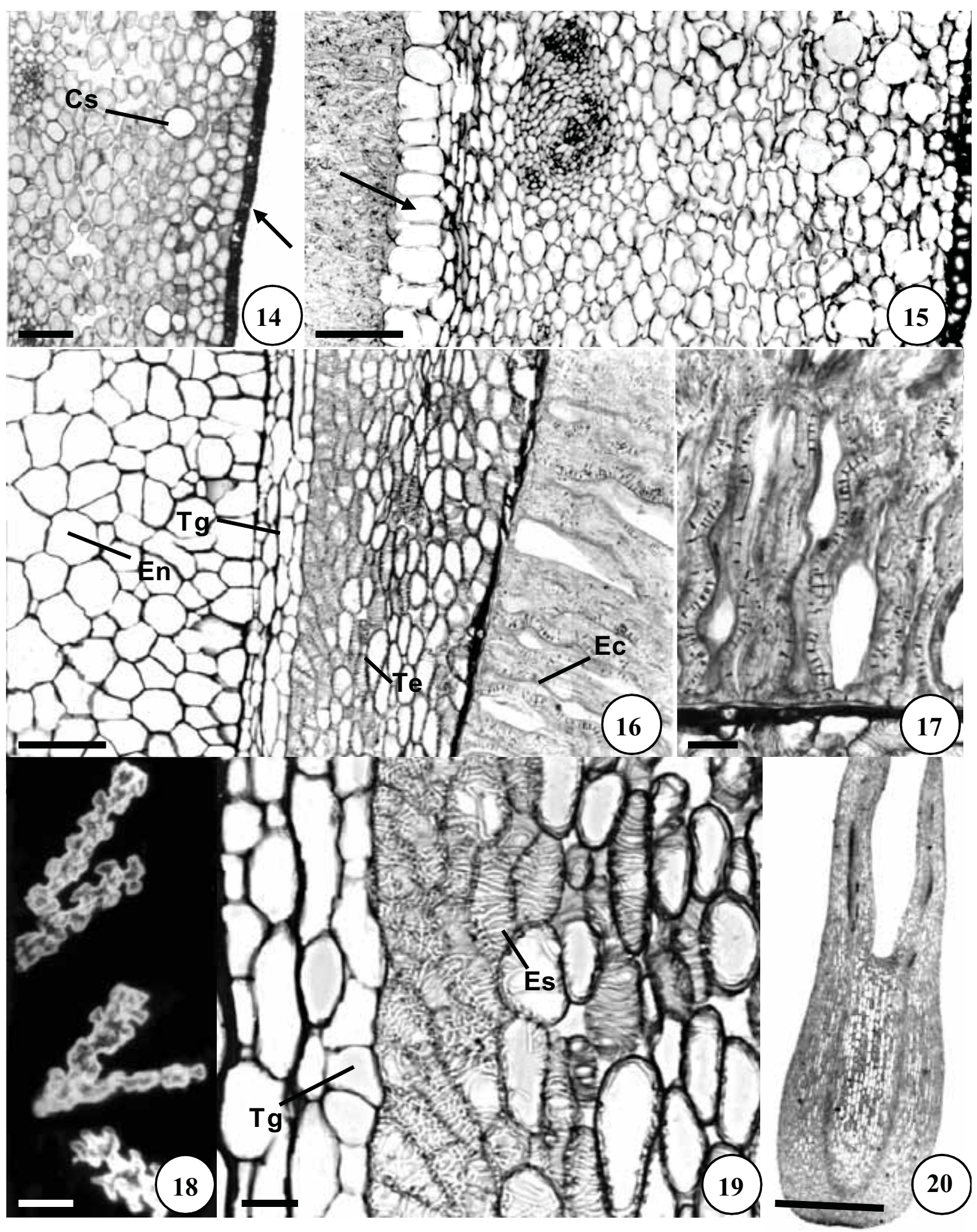

Figuras. 14-20. Secções transversais do pericarpo e da semente. Fig. 14. Epicarpo $(\rightarrow)$ e mesocarpo em detalhe, onde se observam células secretoras (Cs). Barra $50 \mu \mathrm{m}$. Fig. 15. Estrato mais interno do mesocarpo, com células de aspecto diferenciado, ocorrendo junto ao endocarpo $(\rightarrow)$. Barra $50 \mu \mathrm{m}$. Fig. 16. Endocarpo (Ec) aderido às diferentes regiões da semente: Te - testa, Tg - tégmem, En - endosperma. Barra $150 \mu \mathrm{m}$. Fig. 17. Detalhe das esclereídes que formam o endocarpo. Barra $25 \mu \mathrm{m}$. Fig. 18. Esclereídes ramificadas isoladas, denominadas "idioesclereídes". Contraste de fase. Barra $25 \mu \mathrm{m}$. Fig. 19. Detalhe da semente, mostrando os espessamentos (Es) nas células da testa, e os estratos célulares que constituem o tégmem (Tg). Barra $25 \mu$ m. Fig. 20. Embrião isolado na fase de torpedo. Barra $150 \mu \mathrm{m}$. 


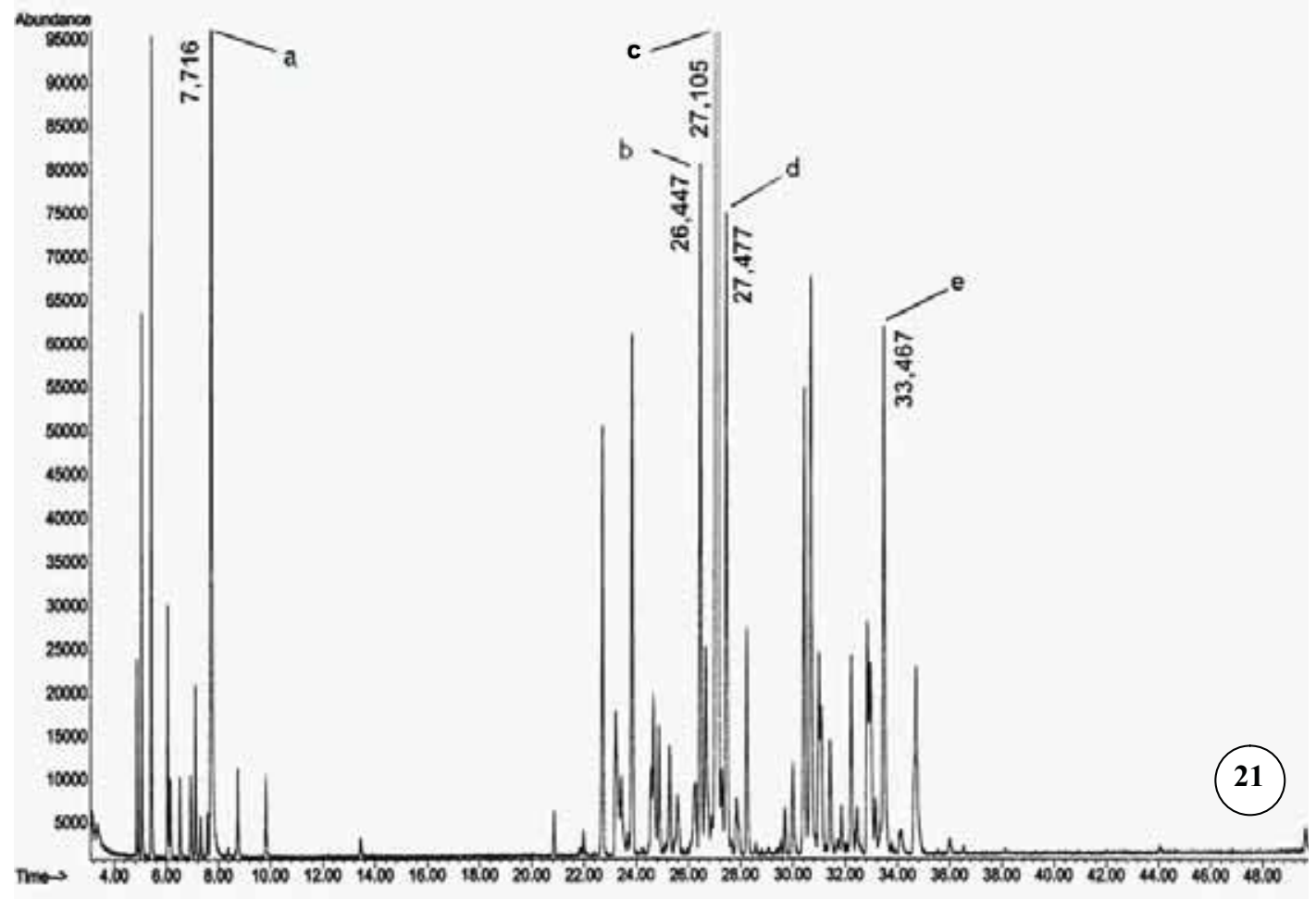

46

Figura 21. Ampliação do cromatograma do óleo essencial extraído dos frutos de $H$. omphalandra. a - $\beta$ felandreno; $\mathrm{b}$ - germacreno D; c - biciclogermacreno; $\mathrm{d}$ - $\alpha$ - bulneseno; e - valerianol.<smiles>C=C1C=CC(C(C)C)CC1</smiles>

a

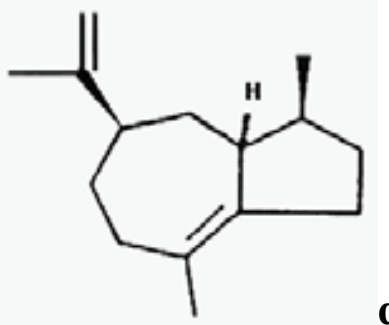<smiles>C=C(/C=C/C(CC/C(C)=C/C)C(C)C)CC</smiles>

b<smiles>CC/C=C\C(C)=CC1C2CCC(C)=CCC12C</smiles><smiles>C[C@H]1CCC=C2CC[C@@H](C(C)(C)O)C[C@@]21C</smiles>

e<smiles>CC1CCC2CC1C2(C)C</smiles>
f

Figura 22. Constituintes químicos majoritários do óleo essencial dos frutos de H. omphalandra, além do ß-pineno que apresenta um esqueleto típico do tipo pinano. a - B-felandreno; $b$ - germacreno D; c - biciclogermacreno; $d$ - $\alpha$ - bulneseno; e - valerianol; f - B-pineno. 


\section{REFERÊNCIAS}

Adams RP 1995. Identification of essential oil components by gas chromatography/ mass spectroscopy. Carol Stream, Illinois: Allured Publishing Corporation.

Adams RP 2001. Identification of essential oil components by gas chromatography/ mass spectroscopy. $2^{\text {nd }}$ edition, Carol Stream, Illinois: Allured Publishing Corporation.

Agra MF, França PF, Barbosa-Filho JM 2007. Synopsis of the plants known as medicinal and poisonous in Northeast of Brazil. Rev Bras Farmacogn 17: 114140.

Andrade EHA, Zoghbi MGB, Machado LB 2004. Seasonal variation and atractylone in the essential oil of Siparuna guianensis Aublet. Revista Brasileira de Plantas Medicinais 6: 62-64.

Antonio TM; Waller GR; Mussinan CJ 1984. Monimiaceae. I. Composition of essencial oil from the leaves of Siparuna guianensis. Chem Ind (London) 14: 514515.

Anvisa 2005. Agência Nacional de Vigilância Sanitária (ANVISA). RDC $n^{\circ} 48$ de 16/03/2004. In: http://www. anvisa.gov.br, acessada em Novembro de 2005.

APG 2003. Angiosperm Phylogeny Group An update of the Angiosperm Phylogeny Group classification for the orders and families of flowering plants: APG II. Bot J Linn Soc 141: 399-436.

Baas P, Gregory M 1985. A survey of oil cells in the dicotiledons with comments on their replacement by and joint occurence with mucilage cells. Isr J Bot 34: $67-186$.

Barbosa-Filho JM, Cunha RM, Dias CS, Athayde-Filho PF, Silva MS, Cunha EVL, Machado MIL, Craveiro AA, Medeiros IA 2008. GC-MS Analysis and cardiovascular activity of the essential oil of Ocotea duckei. Rev Bras Farmacogn 18: 37-41.

Barroso GM, Morim MP, Peixoto AL, Ichaso CLF 1999. Frutos e sementes: morfologia aplicada à sistemática de dicotiledôneas. Viçosa: Editora UFV.

Barroso GM, Peixoto AL, Ichaso CLF, Guimarães EF, Costa CG 2002. Sistemática das Angiospermas do Brasil. Vol. I. $2^{a}$ edição, Viçosa: Editora UFV.

Brandão MGL, Cosenza GP, Moreira RA, Monte-Mor RLM 2006. Medicinal plants and other botanical products from the Brazilian Official Pharmacopoeia. Rev Bras Farmacogn 16: 408-420.

Brandão MGL, Zanetti NNS, Oliveira GRR, Goulart LO, Monte-Mor RLM 2008. Other medicinal plants and botanical products from the first edition of the Brazilian Official Pharmacopoeia. Rev Bras Farmacogn 18: 127-134.

Bruneton J 1991. Elementos de fitoquimica y de farmacognosia. Editorial Acribia, S.A. Zaragoza, España.

Carneiro CMTS, Neves LJ, Pereira EFR, Pereira NA 1989. Mecanismo tóxico de comigo-ninguém-pode, Dieffenbachia picta Schott., Araceae. Rev Bras Farm 70: 11-13.

Dahlgren RMT 1980. A revised system of classification of the Angiosperm. Bot J Linn Soc 80: 91-124.

El-Seedi H, Ghia F, Torsell KBG 1994. Cadinane sesquiterpenes from Siparuna macrotepala. Phytochemistry 35: 1495-1497.
Endress PK 1980. Ontogeny, function and evolution of extreme floral construction in Monimiaceae. Plant Syst Evol 134: 79-120.

Endress PK, Igersheim A 1997. Gynoecium diversity and systematics of the Laurales. Bot J Linn Soc 125: 93168.

Esau K 1977. Anatomy of the seed plants. $2^{\text {nd }}$ ed., New York: Ed. Jonh Villey \& Sons.

Fahn A 1985. Anatomía vegetal. $3^{\mathrm{a}}$ ed., Madrid: Ediciones Pirámide S.A.

Ferreira LS, Marsola FJ, Teixeira SP 2006. Anatomia dos órgãos vegetativos de Dieffenbachia picta Schott (Araceae) com ênfase na distribuição de cristais, laticíferos e grãos de amido. Rev Bras Farmacogn 16 (Supl.): 664-670.

Fischer DCH, Kato ETM, Oliveira F 1998. Caracterização farmacognóstica de limoeiro-bravo - Siparuna apiosyce (Mart.) A. DC.- Monimiaceae. Lecta 16: 9-28.

Gottlieb OR 1972. Quimio-sistemática: um método para a busca de óleos essenciais. An Acad Bras Cienc 44 (Supl.): 9-21.

Gottlieb OR, Salatino A 1987. Função e evolução de óleos essenciais e de suas estruturas secretoras. Ciência e Cultura 39: 707-715.

Guimarães DJ, Oliveira BAD, Marquete O, Magalhães HG, Monteiro-Neto H 1979. Contribuição ao estudo das plantas tóxicas brasileiras: Cestrum sendtnerianum Sendt. Arquivos do Jardim Botânico do Rio de Janeiro 23: 91-96.

Harris JG, Harris MW 2001. Plant identification terminology. $2^{\text {nd }}$ ed., Utah: Spring Lake Publishing.

Jennet-Siems K, Kraft C, Siems K, Jakupovic J, Solis PN, Gupta MP, Bienzle U 2003. Sipaucins AC, sesquiterpenoids from Siparuna pauciflora. Phytochemistry 63: 77-381.

Johansen DA 1940. Plant Microtecnique. $1^{\text {st }}$. ed. Mc Graw Hill Company.

Jorge-Neto J, Valentin RL, Mancini B 1989. Análise cromatográfica do óleo essencial do boldo-do-Chile: determinação quantitativa. Rev Cienc Farm 11: 181187.

Judd WS, Campbell CS, Kellogg EA, Stevens PF, Donoghue MJ 2002. Plant systematics - a phylogenetic approach. $2^{\text {nd }}$ ed., Sinauer associates Inc.

Leitão GG, Lopes D, Menezes FS, Kaplan MAC, Craveiro AA, Alencar JW 1991. Essential oils from Brazilian Aristolochia. J Essent Oil Res 3: 403-408.

Leitão GG, Simas NK, Soares SSV, Brito APP, Claros BMG, Brito TBM, Monache FD 1999. Chemistry and pharmacology of Monimiaceae: a special focus on Siparuna and Mollinedia. J Ethnopharmacol 65: 87102.

Lorence DH 1985. A monograph of the Monimiaceae (Laurales) in the Malgasy region (Southwest Indian ocean). Ann Mo Bot Gard 72: 1-165.

Lorence DH 1987. The fruits of Decarydendron (Monimiaceae). Ann Mo Bot Gard 74: 445-446.

MacLafferty FW, Stanffer DB 1989. Registry of mass spectral data, Vol. I; II. New York: Wiley-Interscience Publishers.

Mendes BG, Machado MJ, Falkenberg M 2006. Triagem de glicolipídios em plantas medicinais. Rev Bras 
Farmacogn 16: 568-575.

Metcalfe CR 1987. Anatomy of the Dicotyledons. Vol. III. $2^{\text {a }}$ ed. Oxford: Oxford Claredon Press.

Milanez FR, Monteiro-Neto H 1956. Origem dos laticíferos do embrião de Euphorbia pulcherrima Willd. Rodriguésia 18/19(30/31): 351-424.

Money LL, Bailey IW, Swamy BGL 1950. The morphology and relationships of the Monimiaceae. Journal of the Arnold Arboretum 31: 372-403.

Morais PLR, Paoli AAS. 1996 Morfologia de frutos e sementes de Cryptocaria moschata Nees \& Martius ex Nees, Endlicheria paniculata (Sprengel) Mac Bride e Ocotea catharinensis Mez (Lauraceae). Rev Bras Sementes 18: 17-27.

Moreira DL, Simas NK, Leitão GG 2001. Essential oils from four Brazilian Mollinedia. Rev Bras Farm 82: 4345.

Occhioni A, Lyra MEM 1948. Contribuição ao estudo das Monimiáceas medicinais brasileiras. Arquivos do Jardim Botânico do Rio de Janeiro 8: 253-273.

Palma S, Luján C, Llabot JM, Barboza G, Manzo RH, Allemandi DA 2002. Design of Peumus boldus tablets by direct compression using a novel dry plant extract. Int J Pharm 233: 191-198.

Panizza S, Scavone O, Rocha AB 1982. Morfodiagnose da maconha (Cannabis sativa L.). Rev Cienc Farm 4: 39-45.

Peixoto AL 1976. Monimiaceae do Brasil. O gênero Hennecartia Poisson. Bradea 2: 71-77.

Peixoto AL, Reitz R, Guimarães EF 2001. Monimiáceas. In: Reis A (ed.). Flora Ilustrada Catarinense. Itajaí: Herbário Barbosa Rodrigues.

Pietta P, Mauri P, Manera E, Ceva P 1988. Determination of isoquinoline alkaloids from Peumus boldus by highperformance liquid chromatography. $J$ Chromatogr A 457: 442-445.

Priestap HA, van Baren CM, Lira PL, Coussio JD, Bandoni AL 2003. Volatile constuents of Aristolochia argentina. Phytochemistry 63: 221-225.

Rao TA, Bhupal OP 1973. Typology of sclereids. Proceedings of the Indian Academy of Sciences 80 B: 41-55.

Ruiz ALTG, Taffarello D, Souza VHS, Carvalho JE 2008. Farmacologia e toxicologia de Peumus boldus e Baccharis genistelloides. Rev Bras Farmacogn 18: 295-300.

Ruzin SE 1999. Plant microtechnique and microscopy. New York/ Oxford: Oxford University Press.

Schenkel EP, Zannin M, Mentz LA, Bordignon SAL, Irgang B 2002. Plantas tóxicas. Pp. 767-800. In: Simões CMO et al. (org.) Farmacognosia: da planta ao medicamento. $4^{\mathrm{a}}$ ed. Porto Alegre/Florianópolis: Ed. Universidade/ UFRGS/ Ed. da UFSC.

Simões CMO, Spitzer V 2002. Óleos voláteis. Pp. 397-425. In: Simões CMO et al. (org.) Farmacognosia: da planta ao medicamento. $4^{\text {a }}$ ed. Porto Alegre/Florianópolis: Ed. Universidade/UFRGS/ Ed. da UFSC.

Smith FH, Smith EC 1942. Anatomy of the inferior ovary of Darbya. Am Jf Bot 29: 464-471.

Soares-Silva LH, Barroso GM 1992. Fitossociologia do estrato arbóreo da floresta na porção norte do Parque Estadual da Mata dos Godoy, Londrina-PR. Congresso da Sociedade Botânica de São Paulo,
Campinas: Sociedade Botânica de São Paulo. Pp. 101-112.

Souza LA, Moscheta IS, Mourão KSM 2003. Fruto. Pp. 375398. In: Apezzato-da-Glória B \& Carmelo-Guerreiro SM (org.). Anatomia Vegetal. Viçosa, MG: Ed. UFV.

Valente MC, Silva NMF, Guimarães DJ 1994. Morfologia e anatomia do fruto de Laguncularia racemosa (L.) Gaernt. F. (Combretaceae). Arquivos do Jardim Botânico do Rio de Janeiro 32: 39-50.

Veloso HP, Rangel-Filho ALR, Lima JCA 1991. Classificação da vegetação brasileira adaptada a um sistema universal. Rio de Janeiro: IBGE.

Vieira PC, Fernandes JB, Andrei CC 2002. Plantas inseticidas. Pp. 751-766. In: Simões CMO et al. (org.) Farmacognosia: da planta ao medicamento. $4^{\mathrm{a}}$ ed. Porto Alegre/Florianópolis: Ed. Universidade/ UFRGS/ Ed. da UFSC. 